\title{
Investigation of human papillomavirus by hybrid capture II in cervical carcinomas including 113 adenocarcinomas and related lesions
}

\author{
M.A.R. MOREIRA*, A. LONGATO-FILHO†キ, E. TAROMARU§, G. QUEIROZ\|, L.F. JUBÉ\|, \\ S.A. PINTO\| \& F.C. SCHMITT $\# \#$ \\ ${ }^{*}$ Department of Pathology, School of Medicine, Federal University of Goiás, Goiânia, Brazil; fInstituto Adolfo \\ Lutz, São Paulo, Brazil; ¥Life and Health Sciences Research Institute, School of Health Sciences, University \\ of Minho, Braga, Portugal; §Digene Brasil, São Paulo, Brazil; //Hospital Araújo Jorge, Goiânia, Brazil; \\ 9IPATIMUP, Porto, Portugal; and \#School of Medicine, University of Porto, Portugal
}

\begin{abstract}
Moreira MAR, Longato-Filho A, Taromaru E, Queiroz G, Jubé LF, Pinto SA, Schmitt FC. Investigation of human papillomavirus by hybrid capture II in cervical carcinomas including 113 adenocarcinomas and related lesions. Int J Gynecol Cancer 2006;16:586-590.

Hybrid capture is an easy and highly sensitive technique for screening population due to its capacity to detect malignant and premalignant lesions of the cervix. To evaluate its sensitivity, we investigated the frequency of high-risk human papillomavirus (HPV) infection and its correlation with glandular malignant lesions, analyzing a total of $\mathbf{1 1 3}$ cases of adenocarcinomas and related lesions. High-risk HPV was investigated using a hybrid capture II (HC2) assay. Samples were collected in two different ways: either brushed directly from surgical specimens before fixation or collected from the patients. We also investigated the frequency of HPV in squamous malignant lesions, 65 squamous cell carcinomas (SCC) and 66 in situ squamous cell carcinomas (ISSCC), to compare the occurrence of HPV for these lesions. The 113 glandular lesions comprised 62 invasive adenocarcinomas (IAC), 8 in situ adenocarcinomas (ISAC), 26 IAC plus SCC, and 17 adenosquamous cells carcinomas (ASCC). The HPV-positive reactions were as follows: 51 (82.2\%) in IAC, $8(100 \%)$ in ISAC, $25(96.1 \%)$ in IAC plus SCC, and $14(82.3 \%)$ in ASCC. HC2-positive results in the squamous malignant lesions were as follows: 58 of $63(89.0 \%)$ for SCC and 94 of 103 (91.2\%) for ISSCC. High-risk HPV infection was quite similar for glandular and pure squamous invasive malignant lesions, $82.2 \%$ and $89.0 \%$, respectively, indicating that high-risk HPV is also highly prevalent in glandular lesions. Although hybrid capture proved to be an excellent adjunctive technique, we do not believe its results merit replacing the Pap smear as a screening tool.
\end{abstract}

KEYWORDS: adenocarcinoma, cervical intraepithelial lesion, HPV, hybrid capture II, squamous cells carcinoma.

Cervical cancer is distributed throughout the world, afflicting 500,000 women annually. The most important risk factor for the development of this condition is the human papillomavirus (HPV) infection. It is believed that $80 \%$ of primary cancers begin from preexisting squamous dysplasia. With respect to glandular epithelium malignancies, adenocarcinomas account for about $20 \%$ of invasive carcinomas, which probably arise from in situ adenocarcinomas (ISAC) ${ }^{(1)}$.

Address correspondence and reprint requests to: Fernando $\mathrm{C}$. Schmitt, MD, PhD, MIAC, IPATIMUP, Rua Roberto Frias s/n, 4200 Porto, Portugal. Email: fschmitt@ipatimup.pt
Interestingly, the incidence of adenocarcinoma is increasing mainly in developed countries ${ }^{(1,2)}$, and it is currently thought to be more significant in large cities due to the increased probability of HPV infections.

Glandular malignant lesions, namely, ISAC, are frequently overlooked because clinical, colposcopic, and cytologic parameters are unfamiliar and bypassed by concomitant squamous alterations. Additionally, more than $50 \%$ of ISAC are mixed diseases with a squamous lesion counterpart ${ }^{(3)}$. Indeed, traditional methods have poor sensitivity to detect precursor lesions of glandular carcinomas. HPV status has a significant impact when correlated with age at diagnosis but not cytology ${ }^{(4)}$. 
Cytology is poorly reproducible for ISAC diagnoses because of its high rates of false-negative results ${ }^{(5)}$.

High-risk HPV status in ISAC, coexisting or not with high-grade intraepithelial lesion (HSIL), seems to be different. The frequency of high-risk HPV genotypes is similar in patients with ISAC alone and with ISAC coexisting with HSIL but significantly different for patients with HSIL without ISAC ${ }^{(6)}$. The distribution of HPV types detected in invasive squamous cell carcinomas (SCC) and adenocarcinoma (AC) was found to be also different and probably associated with variable cofactors ${ }^{(7)}$.

For high-grade squamous lesions, the sensitivity of testing DNA-HPV is superior to cytology but less spe$\mathrm{cific}^{(8)}$. However, HPV-DNA typing is very useful as an adjunct in distinguishing endocervical and endometrial adenocarcinoma ${ }^{(9)}$ and, in combination with cytology, in the follow-up of patients treated for HSIL ${ }^{(10)}$. Under routine conditions with liquid-based cytology, hybrid capture II (HC2) assay has enhanced sensitivity when compared to in situ hybridization ${ }^{(11)}$ for detecting HPV infection. DNA-HPV-positive cases in atypical glandular cells of undetermined significance, as determined by polymerase chain reaction (PCR) or $\mathrm{HC} 2$, have a significant negative predictive value and a higher positive predictive value for significant disease than atypical squamous cells ${ }^{(12)}$. Actually, HPV testing for atypical glandular cells is strongly recommended for management of these patients ${ }^{(13)}$.

Prognostic factors in uterine cervix adenocarcinoma have been recently revised. Longest survival is found for patients with disease in its early stages, of younger age, and after primary surgery ${ }^{(14)}$. Otherwise, mitotic and apoptotic indexes, and the ratio of both, correlate adenocarcinoma to patient survival ${ }^{(15)}$.

Currently, it is thought that by adding high-risk HPV testing to cervical screening, the invasive adenocarcinomas (IAC) and ISAC frequently missed in population-based screening programs might be enhanced. Additionally, the identification of a number of proteins related to HPV infection has also improved the comprehension of some biologic events involved in adenocarcinoma carcinogenesis ${ }^{(16)}$. The expression of the wild or mutant p53 type seems to be slightly prevalent in IAC negative for HPV by means of PCR analysis, while p16 ${ }^{\text {INK4a }}$ expression, a potential marker for E7 function, is significantly related to IAC positive for high-risk $\mathrm{HPV}^{(16)}$. Conversely, the analysis of cyclindependent kinase inhibitors may be useful for clinical outcome; the combination of low expression of p27 (Kip1) and high p16 ${ }^{\mathrm{INK} 4 \mathrm{a}}$ expression strongly favors a poor prognosis ${ }^{(17)}$.

Herein, to test its sensitivity, we studied the occurrence of high-risk HPV infection as assessed by HC2 method in patients with uterine cervix IAC and ISAC and compared it with other epithelial malignancies. To exclude any factor that could lead to a false-negative result, our research was initiated on surgical specimens and the results were compared with results obtained using samples taken directly from patients.

\section{Materials and methods}

Material for examination was brushed from surgical specimens or collected directly from patients submitted for surgical treatment at four hospitals, Araújo Jorge Hospital, Cancer Hospital of Anápolis, Centro Materno Infantil, and Nascer Cidadão, and from the Pathology Department of the School of Medicine of the Federal University of Goiás, Goiania, in Goias State, Brazil, during the years 2002 and 2003. We also investigated the frequency of high-risk HPV in squamous malignant lesions to compare the frequencies of HPV for both glandular and squamous lesions.

High-risk HPV was investigated using an HC2 assay. Samples were collected in two different ways: first, directly from the lesion of surgical specimens before fixation to allow the capture procedure. The specimens were brushed directly and the samples immediately placed in specimen transport medium (STM) (Digene Co., Gaithersbourg, MD). Second, other samples were collected directly from patients according to the method suggested by instructions in the $\mathrm{Di}$ gene collection kit and placed in vials with universal collection medium (UCM) from the Digene DNACitoliq liquid-based cytology system (Digene Brasil, São Paulo, Brazil). These samples were also submitted to cytologic examination, the data of which are not presented in this paper.

The HC2 protocol was performed according to the instructions of the manufacturer. In estimation of results, samples with a relative light unit $>1$ were considered positive. Only high-risk HPV types $(16,18,31$, $33,35,45,51,52$, and 56) were tested. Briefly, after sample denaturation, the DNA/RNA hybridization step was performed and the hybrids were subsequently captured by anti-RNA/DNA antibody coated onto the surface of microplate cavities. The immobilized hybrids reacted with antihybrid antibody conjugated to alkaline phosphatase and were detected with chemoluminescent substrate.

\section{Results}

A total of 113 cases of adenocarcinomas and related lesions as well as 166 squamous lesions were analyzed. From these cases, 89 adenocarcinomas and 106 
squamous lesions were collected directly from surgical specimens and placed in STM; the remaining 24 adenocarcinomas and 60 squamous lesions were collected directly from the patients and placed in UCM.

Of the 113 glandular lesions, we observed 62 IAC, 8 ISAC, 26 IAC plus SCC, and 17 adenosquamous cells carcinomas (ASCC). The high-risk HPV-positive reactions were as follows: $51(82.2 \%)$ in IAC, $8(100 \%)$ in ISAC, $25(96.1 \%)$ in IAC plus SCC, and $14(82.3 \%)$ in ASCC. The squamous malignant lesions exhibited the following capture assay for high-risk HPV results: 58 of $63(89.0 \%)$ SCC and 94 of 103 in situ SCC (91.2\%) were positive for high-risk HPV. In our series, highrisk HPV infection was quite similar for glandular and squamous invasive malignant lesions, $86.7 \%$ and $91.5 \%$, respectively. For in situ malignant lesions, HPVpositive reactions were slightly less frequent in the squamous lesions $(91.2 \%)$ than in glandular lesions $(100 \%)$. The overall distribution of the positive highgrade DNA-HPV testing and histopathologic classification is shown in Table 1. Table 2 exhibits the distribution of HC2 in different glandular and squamous lesions in samples collected in STM. Importantly, the DNA-HPV high-risk HC2 reaction was 100\% positive in ISAC of the cervix and $57.14 \%$ in adenosquamous carcinoma. Additionally, Table 3 confirms the same $100 \%$ of DNA-HPV HC2-positive reactions in cases of ISAC but shows $100 \%$ of HC2-positive reaction in ASCC, as opposed to the samples directly collected from the surgical specimens. Table 4 shows the distribution of DNA-HPV high-risk status according to the histologic subtypes of adenocarcinomas.

\section{Discussion}

The overall incidence of adenocarcinoma worldwide has changed significantly during the past years, rang-

Table 1. General distribution of the positive reactions for high-grade DNA-HPV in glandular malignancies and related lesions and in squamous cell malignant lesions

\begin{tabular}{|c|c|c|c|}
\hline Histologic diagnoses & $\begin{array}{l}\text { Number } \\
\text { of cases }\end{array}$ & $\begin{array}{l}\text { High grade } \\
\text { HPV-positive } \\
\text { reaction }\end{array}$ & $\%$ \\
\hline ISAC & 8 & 8 & 100.0 \\
\hline Adenocarcinoma & 62 & 51 & 82.2 \\
\hline Adenocarcinoma plus SCC & 26 & 25 & 96.1 \\
\hline Adenosquamous carcinoma & 17 & 14 & 82.3 \\
\hline $\begin{array}{l}\text { Subtotal (lesions } \\
\text { with glandular component) }\end{array}$ & 113 & 98 & 86.7 \\
\hline In situ SCC & 103 & 94 & 91.2 \\
\hline Invasive SCC & 63 & 58 & 89.0 \\
\hline Subtotal (squamous lesions) & 166 & 152 & 91.5 \\
\hline Total $=279$ & & 250 & 89.6 \\
\hline
\end{tabular}

(C) 2006 IGCS, International Journal of Gynecological Cancer 16, 586-590
Table 2. Distribution of the high-grade DNA-HPV-positive reactions in samples collected directly from the surgical specimens with STM

\begin{tabular}{lrrrr}
\hline $\begin{array}{l}\text { Histologic } \\
\text { diagnoses }\end{array}$ & $\begin{array}{l}\text { Number } \\
\text { of cases }\end{array}$ & $\begin{array}{l}\text { HPV- } \\
\text { positive } \\
\text { cases }\end{array}$ & $\begin{array}{l}\text { HPV- } \\
\text { negative } \\
\text { cases }\end{array}$ & $\%$ \\
\hline ISAC & 5 & 5 & 0 & 100.00 \\
Adenocarcinoma & 58 & 47 & 11 & 81.03 \\
Adenocarcinoma plus SCC & 19 & 18 & 1 & 94.73 \\
Adenosquamous carcinoma & 7 & 4 & 3 & 57.14 \\
In situ SCC & 51 & 47 & 4 & 92.15 \\
SCC & 55 & 50 & 5 & 90.90 \\
Total & 95 & 171 & 24 & 87.69 \\
\hline
\end{tabular}

ing from $5 \%$ in five decades ago to $25 \%$ currently $^{(18)}$. There is conclusive evidence that HPV infection is a necessary cause to cervical cancer; however, the discrepancy between the high frequency of HPV infections among young, sexually active women and the relative low incidence of cervical neoplasia is still to be clearly understood ${ }^{(19)}$.

HPV testing will presume increasing importance on daily routine, although thoughtful evaluation of the results is strongly suggested, but analogously, it is well accepted that it is highly specific in segregating true squamous and glandular lesions from their mimics ${ }^{(20)}$. The results herein discussed clearly demonstrate the strong association of in situ and invasive lesions with high-grade HPV infection for both glandular and squamous origins. In fact, the results of HPV testing achieved in our study were remarkable since the adenocarcinomas with HPV-related infections achieved with PCR amplification range to $70 \%{ }^{(21)}$. For laboratorial practices, the association of HPV testing in cases where glandular lesions exhibit doubtful interpretation should be seriously considered because cytology lacks sensitivity and specificity in many circumstances $^{(22)}$. On the other hand, the DNA-HPV-positive

Table 3. Distribution of the high-grade DNA-HPV-positive reactions in samples collected from the patients with UCM

\begin{tabular}{lccll}
\hline $\begin{array}{l}\text { Histologic } \\
\text { diagnoses }\end{array}$ & $\begin{array}{l}\text { Number } \\
\text { of cases }\end{array}$ & $\begin{array}{l}\text { HPV- } \\
\text { positive } \\
\text { cases }\end{array}$ & $\begin{array}{l}\text { HPV- } \\
\text { negative } \\
\text { cases }\end{array}$ & $\%$ \\
\hline ISAC & 3 & 3 & - & 100.00 \\
Adenocarcinoma & 4 & 4 & - & 100.00 \\
$\begin{array}{l}\text { Adenocarcinoma } \\
\text { plus SCC }\end{array}$ & 7 & 7 & - & 100.00 \\
$\begin{array}{l}\text { Adenosquamous } \\
\quad \text { carcinoma }\end{array}$ & 10 & 10 & - & 100.00 \\
$\begin{array}{l}\text { In situ SCC } \\
\text { SCC }\end{array}$ & 52 & 47 & 5 & 90.38 \\
Total & 8 & 7 & 1 & 87.50 \\
\hline
\end{tabular}


Table 4. General distribution of the subtypes of the 113 cases of adenocarcinomas positive for HPV

\begin{tabular}{lcclr}
\hline Histologic subtypes & $\begin{array}{l}\text { Number } \\
\text { of cases }\end{array}$ & $\begin{array}{l}\text { HPV } \\
\text { positive }\end{array}$ & $\begin{array}{l}\text { HPV } \\
\text { negative }\end{array}$ & $\%$ \\
\hline Endocervical & 64 & 59 & 5 & 92.18 \\
Endometrioid & 11 & 10 & 1 & 90.90 \\
Intestinal & 3 & 1 & 2 & 33.33 \\
Endocervical + & 4 & 4 & 0 & 100.00 \\
$\quad$ endometrioid & 5 & 5 & 0 & 100.00 \\
Endocervical + intestinal & 5 & 5 & 0 & 100.00 \\
Viloglandular papilar & 5 & 14 & 3 & 82.35 \\
Adenosquamous & 17 & 0 & 3 & 0.00 \\
Mesonephric carcinona & 3 & 0 & 1 & 0.00 \\
Minimal-deviation & 1 & & & \\
$\quad$ adenocarcinoma & & 98 & 15 & 86.70 \\
Total & 113 & 98
\end{tabular}

HC2 reactions in SCC were slightly inferior to those obtained with PCR; these frequently are close to $100 \%{ }^{(23)}$. Conversely, HPV-associated infection in adenosquamous lesion, believed to comprise around $50 \%$ of cases $^{(24)}$, was higher in our study. Our findings are quite similar to those of Pirog et al. (2000) ${ }^{(25)}$ who used a microdissection procedure to circumscribe the tissue with the presumed alterations and evaluated the presence of HPV in these select fields with PCR assay. With respect to DNA-HPV, they observed positive reactions in $91 \%$ of adenocarcinomas and $100 \%$ of ASCC. Furthermore, Ronnet et al. (1999) ${ }^{(26)}$, using an HC2 method, found $100 \%$ positive DNA-HPV HC2 reaction in cases of in situ carcinoma of the cervix. As a result, the use of HC2 reaction and refined cytologic criteria to improve the management of patients with glandular atypia of undetermined significance was suggested ${ }^{(26)}$. Similar advisement was recently stated by Oliveira et al. (2004) ${ }^{(27)}$. These authors also found DNA-HPVpositive reaction in $100 \%$ of ISAC, similar to our findings.

It is important to stress some points of our study: first, we analyzed a large number of adenocarcinomas and related lesions, more than 20 times those in previous studies ${ }^{(26,27)}$. Second, we tested the hypothesis that the sample collection for HC2 assay performed directly on surgical specimens to be highly specific in terms of quality than samples collected under routine conditions. The material collected on the visible lesion could constrain some variance in the HC2-positive reaction in comparison to those collected directly from patients. Surprisingly, the results obtained from the samples collected from the patients were more frequently positive to DNA-HPV than those achieved from the samples collected directly from the surgical specimens, even though they were not statistically significant. The approach of taking samples directly from the lesion of fresh surgical specimens certainly should be more representative, but it was not. One possible cause for these unexpected results could be due to the use of iodine solution in presurgical proceedings that can inhibit the HC2 reaction in some cases (information from the manufacturer, Digene Manual-Hybrid Capture II).

Another factor that may have contributed to the inhibition of $\mathrm{HC} 2$ reaction in the surgical specimens, especially in the cases of adenosquamous carcinoma, is that some of the cases had been conized and others subjected to previous radiotherapy, data that had not been informed before collection of the material. An additional important detail is that the adenocarcinomas collected from the patients were all of the endometrioid or endocervical type; in the specimens, there was one case of a minimal-deviation adenocarcinoma and one case of a mesonephric adenocarcinoma, the two referred as negative in the study of Pirog et al. ${ }^{(25)}$. One more possible source of bias could be the different liquid mediums used in this study, although STM and UCM are both produced by the same manufacturer and the performance of both mediums to identify HPV is similar ${ }^{(28)}$.

As series involving adenocarcinomas are progressively arising in surgical pathology routine, a critical approach is necessary to understand the biologic behavior of such lesions and to improve the parameters for the diagnosis of such lesions as well as the discrimination of related lesions. The first step, in our view, is to determine the occurrence of HPV infection in those lesions as determined by a molecular method of routine use; other methods of recognized sensitivity are feasible only for research purposes. Further research in this field involves ongoing studies of our group in an attempt to correlate cytologic parameters of glandular and squamous lesions as well as molecular markers for the discrimination of cervical lesions and their prognosis. Currently, we believe that HC2 method can be an important adjunct to, but not a substitute for, a properly done Pap smear.

\section{Acknowledgment}

We wish to express our special thanks to Digene Brasil for kindly supplying the Hybrid Capture kits used in our study.

\section{References}

1 Waggoner SE. Cervical cancer. Lancet 2003;361:2217-25.

2 Boon M, Claasen HHR, Westering RP, Kok LP. Urbanization and the incidence of abnormalities of squamous and glandular epithelium of the cervix. Cancer Cytopathol 2003;99:4-8. 
3 Wright VC. Cervical squamous and glandular intraepithelial neoplasia: identification and current management approaches. Salud Publica Mex 2003;45:S417-29.

4 Andersson S, Larson B, Hjerpe A et al. Adenocarcinoma of the uterine cervix: the presence of human papillomavirus and the method of detection. Acta Obstet Gynecol Scand 2003;82:960-5.

5 Renshaw AA, Mody DR, Lozano RL et al. Detection of adenocarcinoma in situ of the cervix in Papanicolaou tests. Arch Pathol Lab Med 2004;128:153-7.

6 Bekkers RLM, Bulten J, Wiersma-van Tilburg A et al. Coexisting high-grade glandular and squamous cervical lesions and human papillomavirus infections. Br J Cancer 2003;89:886-90.

7 Burk RD, Terai M, Gravitt PE et al. Distribution of human papillomavirus types 16 and 18 variants in squamous cells carcinomas and adenocarcinomas of the cervix. Cancer Res 2003;63:7215-20.

8 Cuzick J, Szarewski A, Hulman G et al. Management of women who test positive for high risk types of human papillomavirus: the HART study. Lancet 2003;362:1871-6.

9 Plunkett M, Brestovac B, Thompson J et al. The value of HPV DNA typing in the distinction between adenocarcinoma of endocervical and endometrial origin. Pathology 2003;35:397-401.

10 Zielinski GD, Rozendaal L, Voorhorst FJ et al. HPV testing can reduce the number of follow up visits in women treated for cervical intraepithelial neoplasia grade 3. Gynecol Oncol 2003;91:67-73.

11 Hesselink AT, van den Brule AJC, Brink AATP et al. Comparison of hybrid capture 2 with in situ hybridization for the detection of highrisk human papillomavirus in liquid-based cervical samples. Cancer 2004;102:11-8.

12 Krane JF, Lee KR, Sun D, Yuan L, Crum CP. Atypical glandular cells of undetermined significance. Am J Clin Pathol 2004;121: $87-92$.

13 Tam KF, Cheung ANY, Liu KL et al. Retrospective review on atypical glandular cells of undetermined significance (AGUS) using the Bethesda 2001 classification. Gynecol Oncol 2003;91:603-7.

14 Baalbergen A, Ewing-Graham PC, Hop WCJ, Struijk P, Helmerhorst TJM. Prognostic factors in adenocarcinoma of the uterine cervix. Gynecol Oncol 2004;92:262-7.

15 Leung TW, Xue WC, Cheung ANY, Khoo US, Ngan HYS. Proliferation to apoptosis ratio as a prognostic marker in adenocarcinoma of uterine cervix. Gynecol Oncol 2004;92:866-72.

16 Zielinski GD, Snijders PJF, Rozendaal L et al. The presence of high risk HPV combined with specific p53 and p16 ${ }^{\mathrm{INK} 4 \mathrm{a}}$ expression patterns points to high-risk HPV as the main causative agent for adenocarcinoma in situ and adenocarcinoma of the cervix. J Pathol 2003;201:535-43.
17 Alfsen GC, Reed W, Sandstad B, Kristensen GB, Abeler VM. The prognostic impact of cyclin dependent kinase inhibitors p21WAF1, p27Kip1, and p16INK4/MTS1 in adenocarcinomas of the uterine cervix: an immunohistochemical evaluation of expression patterns in population-based material from 142 patients with international federation of gynecology and obstetrics stage I and II adenocarcinoma. Cancer 2003;98:1880-9.

18 Smith HO, Tiffany MF, Qualls CR, Key CR. The rising incidence of adenocarcinoma relative to squamous cells carcinoma of the uterine cervix in the United States: a 24-year population-based study. Gynecol Oncol 2000;78:97-105.

19 Richardson H, Kelsall G, Tellier P et al. The natural history of typespecific human papillomavirus infections in female university students. Cancer Epidemiol Biomarkers Prev 2003;12:485-90.

20 Stoler MH. Human papillomavirus biology and cervical neoplasia. Implications for diagnostic criteria and testing. Arch Pathol Lab Med 2003;127:935-9.

21 Andersson S, Rylander E, Larsson B, Strand A, Silfversvärd C, Wilander E. The role of human papillomavirus in cervical adenocarcinoma carcinogenesis. Eur J Cancer 2001;37:246-50.

22 Moriaty AT, Wilbur D. Those gland problems in cervical cytology: faith or fact? Observations from the Bethesda 2001 Terminology Conference. Diagn Cytopathol 2003;28:171-4.

23 Walboomers JMM, Jacobs MV, Manos MM et al. Human papilloma virus is a necessary cause of invasive cervical cancer worldwide. J Pathol 1999;189:12-9.

24 Tase T, Okagaki T, Clark BA et al. Human papillomavirus types and localization in adenocarcinoma and adenosquamous carcinoma of the uterine cervix: a study by in situ DNA hybridization. Cancer Res 1988;48:993-8.

25 Pirog EC, Kleter B, Olgac S et al. Prevalence of human papillomavirus DNA in different histological subtypes of cervical adenocarcinoma. Am J Pathol 2000;157:1055-62.

26 Ronnet BM, Manos MM, Ransley JE et al. Atypical glandular cells of undetermined significance (AGUS): cytopathologic features, histopathologic results, and human papillomavirus DNA detection. Hum Pathol 1999;30:816-25.

27 Oliveira ERZM, Derchain SFM, Rabelo-Santos SH et al. Detection of high-risk human papillomavirus (HPV) DNA by hybrid capture II in women referred due to atypical glandular cells in the primary screening. Diagn Cytopathol 2004;31:19-22.

28 Lörincz A, Anthony J. Advances in HPV detection by Hybrid Capture $^{\circledR}$. Papillomavirus Rep 2001;12:145-53.

Accepted for publication 24, November 2004 